\title{
OPEN Effects of C-type natriuretic peptide on meiotic arrest and developmental competence of bovine oocyte derived from small and medium follicles
}

\author{
Zhenwei Jia ${ }^{\varpi}$ \&ueli Wang
}

The present study aimed to evaluate the effects of C-type natriuretic peptide (CNP) on meiotic arrest and developmental competence of bovine oocyte derived from follicles of different sizes. Collected immature cumulus-oocyte complexes from small follicles $(<3 \mathrm{~mm})$ and medium follicles $(3-8 \mathrm{~mm})$ were cultured for $6 \mathrm{~h}$ in basal medium supplementated without or with $200 \mathrm{nM}$ CNP. We observed that CNP effectively sustained meiotic arrest at germinal vesicle stage in in vitro cultured bovine oocytes from follicles of different sizes. Moreover, CNP treatment significantly improved the levels of cGMP in both cumulus cells and oocytes, as well as the levels of CAMP in oocytes regardless of follicle size. Based on the above results, we tested the effect of a novel in vitro maturation (IVM) system based on CNP-pretreatment, including a pre-IVM phase for $6 \mathrm{~h}$ using $200 \mathrm{nM}$ CNP, followed by a extended IVM phase for $28 \mathrm{~h}$, on developmental competence of bovine oocyte derived from small follicles $(<3 \mathrm{~mm})$ and medium follicles (3-8 $\mathrm{mm}$ ) compared to standard IVM system. The results showed that athough the novel IVM system based on CNP-pretreatment enhanced the developmental potencial of oocytes obtained from large follicles, but had no effect on the developmental comptence of oocytes obtained from small follicles.

It is well established that the developmental capacity of bovine oocytes undergoing in vitro maturation (IVM) is poor $^{1,2}$. The decrease in the developmental competence of in vitro-matured oocytes may be partly due to asynchronous nuclear and cytoplasmic maturation, leading to insufficient cytoplasmic maturity ${ }^{3}$. Thus, synchronization of nuclear and cytoplasmic maturation in antral oocytes arrested at the immature GV-stage is of fundamental importance for successful fertilization and embryo development ${ }^{4}$.

The somatic cell compartment of the antral follicles plays a key role in the maintenance of oocyte meiotic arrest $^{5,6}$. In addition, evidence indicates that oocytes meiotic arrest at the germinal vesicle (GV) stage is associated with the intra-oocyte levels of cAMP and high levels of cAMP within the oocyte maintain meiotic arrest ${ }^{7-9}$. More importantly, C-type natriuretic peptide (CNP), which is expressed at high levels in mural granulosa cells, acts on the receptor natriuretic peptide receptor 2 (NPR2) in cumulus cells to generate cGMP, cyclic GMP then enters the oocyte via gap-junctional communication (GJC) and regulates the levels of cAMP by inhibiting the hydrolyzing activity of specific phosphodiesterase $3 \mathrm{~A}$ (PDE3A), thus maintaining oocytes meiotic arrest ${ }^{10,11}$. Given the inhibitory role of CNP in the modulation of oocyte meiotic maturation, intensive efforts have focused on the development of two-step culture systems using CNP to delay or temporarily prevent spontaneous nuclear maturation, with the aim of promoting cytoplasmic maturation and subsequently improving bovine oocyte developmental competence in vitro ${ }^{11-14}$. Notably, a novel IVM system based on CNP-pretreatment, including a pre-IVM phase for $6 \mathrm{~h}$ using $200 \mathrm{nM}$ CNP, followed by a extended IVM phase for 26-28 h, has demonstrated a remarkable improvement in bovine oocyte developmental comptence ${ }^{11}$.

Oocyte developmental competence is highly correlated with follicle size ${ }^{15}$. Bovine oocytes from small antral follicles $(<3 \mathrm{~mm})$ have low competence to be matured in vitro and to assure early embryo development ${ }^{16}$. Therefore, bovine oocyte from medium antral follicles (MFs, 3-8 $\mathrm{mm}$ ) are commonly used for IVM and in vitro embryo production. Consequently, oocytes from small follicles (SFs, $<3 \mathrm{~mm}$ ) are discarded because of their low 


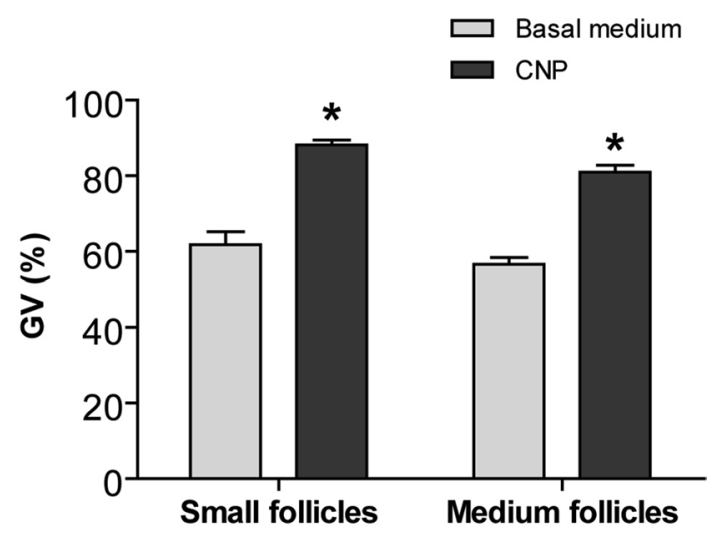

Figure 1. Effect of CNP on meiotic arrest of bovine oocytes cultured in vitro from different sizes follicles. COCs derived from small follicles (SFs) and medium follicles (MFs) were cultured for $6 \mathrm{~h}$ in basal medium without or with $200 \mathrm{nM}$ CNP. The rate of oocyte arrested at the GV stage was examined at the end of culture. Graphs show the mean \pm SEM values of four independent experiments; The asterisks represent significant differences between the two groups with the same size follicle $(P<0.05)$. CNP: C-type natriureticpeptide; COCs: cumulus oocyte complexes; GV: germinal vesicle.

developmental competence, resulting in valuable genetic materials being wasted. Thus, the present study aimed to investigate the effects of CNP on meiotic arrest and developmental competence of bovine oocyte derived from follicles of different sizes, with an emphasis on the efficiency of the novel IVM system based on CNP-pretreatment at improving developmental comptence of bovine oocytes from SFs compared with conventional IVM system.

\section{Results}

Effect of CNP on meiotic arrest in bovine oocytes in vitro. To examine wheather CNP can maintain meiotic arrest in bovine oocytes derived from different size follicles, cumulus-oocyte complexes (COCs) from different size follicles were cultured for $6 \mathrm{~h}$ in basal medium supplementated without or with $200 \mathrm{nM} \mathrm{CNP}$. We found that COCs treated with CNP displayed a significantly higher rate of GV regardless of follicle size, compared to basal group (no CNP treatment) $(P<0.05)$ (Fig. 1).

Effect of CNP on cGMP levels in cumulus cells and oocytes of COCs. To determine whether CNP can stimulate COCs from follicles of different sizes to generate cGMP, COCs from SFs and MFs were cultured for $6 \mathrm{~h}$ in basal medium supplementated without or with $200 \mathrm{nM}$ CNP. The results showed that the levels of cGMP in both cumulus cells and oocytes regardless of follicle size were significantly higher in CNP treatment group than that in basal medium group (no CNP treatment) $(P<0.05)$ (Fig. 2).

Effect of CNP on cAMP levels in cumulus cells and oocytes of COCs. To determine whether CNP can sustain higher levels of cAMP in oocyte, COCs from SFs and MFs were cultured for $6 \mathrm{~h}$ in basal medium supplementated without or with $200 \mathrm{nM} \mathrm{CNP}$. As shown in Fig. 3, CNP treatment significantly improved the cAMP levels in oocytes $(P<0.05)$, but not in cumulus cells regardless of follicle size, compared to the control group (no CNP treatment) $(P<0.05)$ (Fig. 3$)$.

Effect of CNP on CGMP /CAMP levels in cumulus cells and oocytes of COCs via activation of NPR2. As shown in Figs. 2 and 3, CNP elevated the levels of cGMP in cumulus cells and oocyte, as wellas the levels of cAMP in oocyte, suggesting that CNP may activate NPR2. To test this possibility, the NPR2-relative specific, but high-efficient competitive inhibitor Gö6976 $(5 \mu \mathrm{M})^{11}$ together with CNP $(200 \mathrm{nM})$ was added to the basal medium (CNP + Gö6976) during in vitro culture. As shown in Fig. 4, compared to basal medium group, the increased level of cGMP in cumulus cells and oocyte and cAMP in oocyte was no longer observed. Furthermore, compared to CNP-only treatment, the level of cGMP in cumulus cell and oocyte, and cAMP in oocyte was significantly decreased $(P<0.05)$ when COCs were treated by CNP and Gö6976 simultaneously (Fig. 4).

Effect of CNP pre-treatment on bovine oocyte development. To investigate the effect of CNP pretreatment on developmental competence of bovine oocyte derived from follicles of different sizes. A novel IVM system based CNP pretreatment was used, in which bovine oocytes were pre-treated with $200 \mathrm{nM}$ CNP in TCM199 medium supplemented with $0.4 \%$ BSA for $6 \mathrm{~h}$, then subjected to IVM and fertilized after $28 \mathrm{~h} \mathrm{IVM}^{11}$ (Xi et al. 2018). Results showed that this IVM system based CNP pretreatment significantly improved the cleavage and blastocyst rates of oocytes collected from MFs $(P<0.05)$, but not from SFs $(P>0.05)$ following in vitro fertilization (IVF) (Table. 1). In addition, the cell numbers of per blastocyst, considered a marker of embryo quality, was significantly higher in CNP based MFs IVM group compared to other IVM groups $(P<0.05)$ (Table. 1). These findings indicate that although CNP pre-IVM treatment enhanced the developmental potencial of 

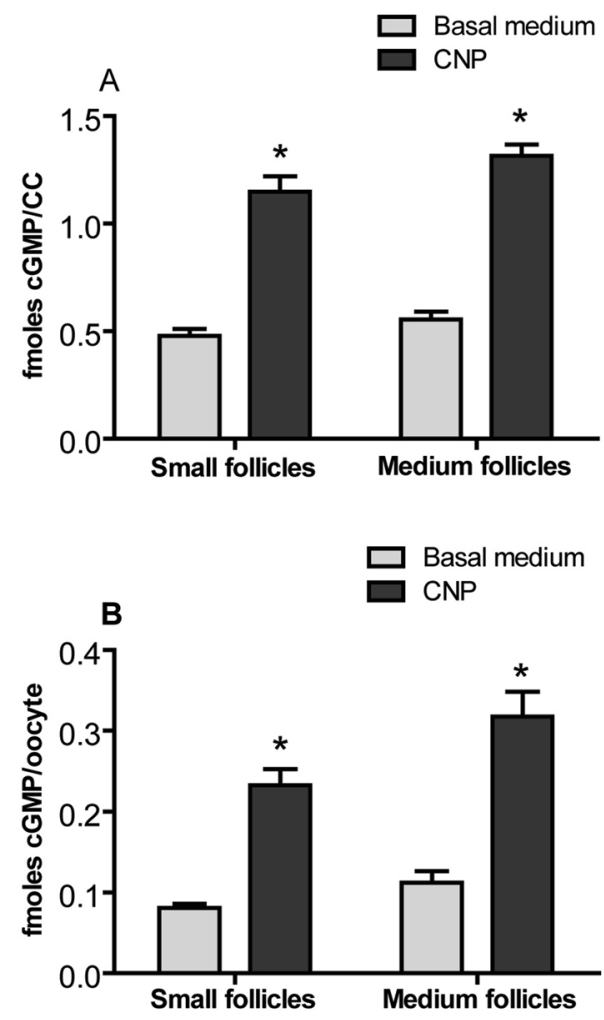

Figure 2. Effect of CNP on the levels of cGMP in bovine cumulus cells and oocytes. COCs derived from small follicles (SFs) and medium follicles (MFs) were cultured for $6 \mathrm{~h}$ in basal medium without or with $200 \mathrm{nM}$ CNP. The levels of cGMP in bovine cumulus cells and oocytes were detected at the end of culture. (A) The levels of cGMP in bovine cumulus cells. (B) The levels of cGMP in bovine oocytes. Graphs show the mean \pm SEM values of four independent experiments; The asterisks represent significant differences between the two groups with the same size follicle $(P<0.05)$.

oocytes obtained from MFs, but had no effect on the developmental comptence of oocytes obtained from SFs $(P>0.05)$.

\section{Discussion}

It is generally accepted that high levels of intra-oocyte cAMP are essential for maintaining the meiotic arrest of mammalian oocytes in vivo ${ }^{17,18}$. In addition to the generation of cAMP from mural granulosa and/or cumulus cells, the oocyte itself can also produce cAMP due to activation of the constitutively active heterotrimeric G protein (Gs)-linked receptors GPR3 or GPR12, which primarily induces meiotic arrest via protein kinase A (PKA)-mediated phosphorylation of the proteins that regulate cyclin dependent protein kinases ${ }^{19}$. An inability to suppress cAMP phosphodiesterase PDE3A activity in mouse oocytes would reduce the levels of cAMP, resulting in meiotic resumption in a gonadotropin-independent manner ${ }^{20,21}$. Moreover, a previous report has indicated that the transfer of cGMP from mouse cumulus cells to oocytes via gap junctions is a critical factor in the inhibition of PDE3 $\mathrm{A}^{22}$. More importantly, it has already been demonstrated that CNP stimulates cGMP production in cumulus cells by activating NPR2, and cGMP diffuses into the oocyte from companion cumulus cells via gap junctions and inhibits oocyte PDE3A activity and cAMP hydrolysis, therebying maintaining meiotic arrest in mouse oocytes ${ }^{10}$. Hence, the CNP induced-cGMP in cumulus cells are crucial for maintaining sufficient intra-oocyte cAMP to inhibit oocyte meiotic resumption in the mice. It has been demonstrated that PDE3A is predominantly expressed in bovine oocytes ${ }^{23}$. Additionally, high levels of cAMP sustained by inhibiting PDE3A activity, can transiently prevent the meiotic resumption of denuded bovine oocytes in vitro ${ }^{20,24}$. In particular, previous reports demonstrated that a PKA stimulator blocked meiotic maturation of bovine oocytes, whereas a PKA inhibitor interfered with the meiotic arrest of bovine oocytes induced by forskolin or cilostamide ${ }^{25,26}$. These findings also support the view that high levels of cAMP sustained in oocytes also plays a key role in the maintenance of meiotic arrest in bovine oocytes ${ }^{27}$. Notably, a recent study demonstrated that in addition to inducing cGMP generation in CCs, CNP can also activate intra-oocyte cGMP production via NPR2 localized in oocyte membranes, sustaining sufficient levels of cAMP to maintain meiotic arrest of bovine oocytes, which is distinct from that known in mouse ${ }^{11}$. Up to date, the research papers published revealed the mechanism underlying the CNP-induced meiotic arrest, primarily using mixed population of oocytes isolated from follicles with a diameter $2-8 \mathrm{~mm}^{11,12}$. However, the effect of CNP on meitic arrest in bovine oocytes isolated from SF with a diameter $<3.0 \mathrm{~mm}$ remain still unclear. Our data confirmed that CNP not only sustained meiotic arrest in bovine oocytes derived from SF with a diameter $<3.0 \mathrm{~mm}$, but also increased the levels of cGMP in both CCs and oocyte, 

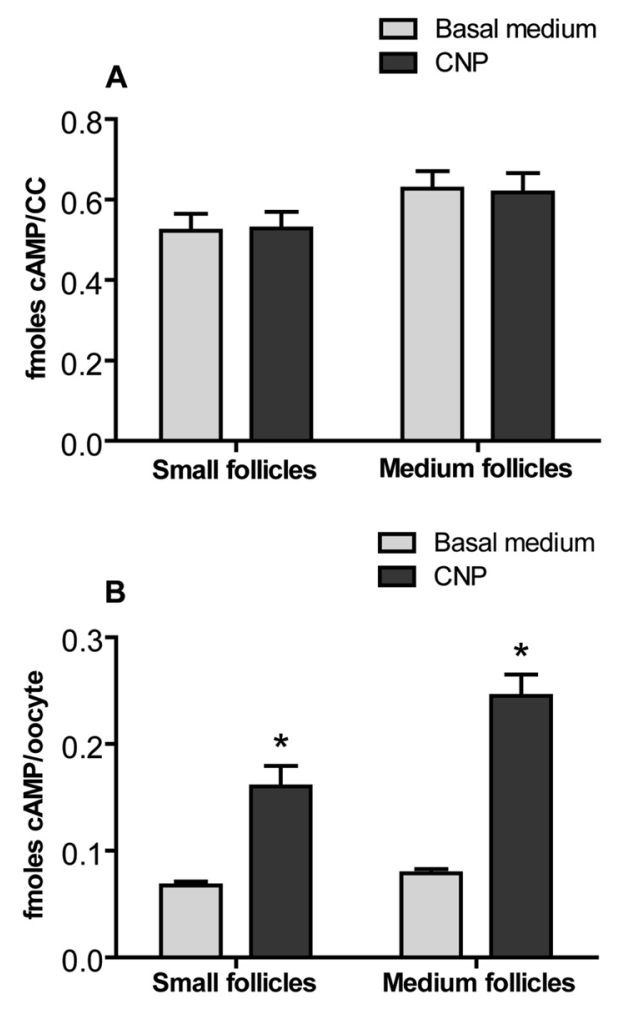

Figure 3. Effect of CNP on the levels of cAMP in bovine cumulus cells and oocytes. COCs derived from small follicles (SFs) and medium follicles (MFs) were cultured for $6 \mathrm{~h}$ in basal medium without or with $200 \mathrm{nM}$ CNP. The levels of cAMP in bovine cumulus cells and oocytes were detected at the end of culture. (A) The levels of cAMP in bovine cumulus cells. (B) The levels of cAMP in bovine oocytes. Graphs show the mean \pm SEM values of four independent experiments; The asterisks represent significant differences between the two groups with the same size follicle $(P<0.05)$.

and the levels of cAMP in oocytes, indicating that CNP can also induce cGMP generation in bovine COCs from SF via NPR2 activation and thus inhibit intra-oocyte cAMP hydrolysis and meiotic resumption. Overall, these findings suggest that the high levels of cAMP and cGMP sustained by CNP/NPR2 signaling pathway plays a key role in maintaining meiotic arrest in bovine oocytes.

Currently, bovine oocytes matured in vitro are developmentally compromised. The low efficiency of oocyte IVM technology limits the exploration and utilization of oocyte sources from cattle with desirable traits. Extensive studies using meiotic inhibitors have been conducted to optimize the bovine IVM system; nevertheless, the role of these meiotic inhibitors in enhancing the development of bovine oocytes remains controversial ${ }^{28-31}$. Notably, several studies have demonstrated that CNP maintains meiotic arrest of immature oocytes after removal from antral follicles in different animal species ${ }^{11,32,33}$. These finding suggest CNP could be used as an effective and safe factor to optimize in vitro maturation culture system, thereby facilitating the developmental competence of oocytes matured in vitro. Indeed, the potential of CNP to improve oocyte competence and embryo quality in mammals has alreadly been demonstrated in large animal and human models ${ }^{11,33-35}$. Among these models, a novel IVM system based on CNP-pretreatment, which includes a pre-IVM phase for $6 \mathrm{~h}$ using $200 \mathrm{nM} \mathrm{CNP}$, followed by a extended IVM phase for $26-28 \mathrm{~h}$, has been found to significantly promoted cytoplasmic maturation in bovine oocytes from follicles with a diameter $2-8 \mathrm{~mm}$, as reflected by an improved developmental competence ${ }^{11}$. Similarly, our results showed that the novel IVM system based on CNP-pretreatment significantly improved the developmental comptence of bovine oocytes from MFs with a diameter 3-8 $\mathrm{mm}$. The mechanisms by which CNP improved bovine oocyte cytoplasmic maturation might be due to elevated levels of maternal mRNA and proteins during meiotic arrest in vitro, resulting in an increased rate of embryo development beyond the "maternal-toembryonic transition" stage ${ }^{36}$.

Oocyte quality is associated with follicle size ${ }^{15}$. The present study reported a significantly higher cleavage and blastocyst rates in MFs oocytes than those of SF-derived oocytes, which was similar with previous findings ${ }^{16,37}$. At present, the mixed population of bovine oocytes isolated from MFs with a diameter 3-8 $\mathrm{mm}$ were commonly used for in vitro embryo production ${ }^{38-40}$. However, whether the novel IVM system based on CNP-pretreatment can improve the developmental comptence of bovine oocytes from SF with a diameter $<3 \mathrm{~mm}$ is still unkown. The present study confirmed that CNP pre-IVM treatment had no effect on the developmental comptence of bovine oocytes obtained from SFs, suggesting a short period of meiotic arrest prior to IVM using CNP fails to adequately support cytoplasmic maturation of bovine oocyte from SFs with a diameter $<3 \mathrm{~mm}$. Oocyte developmental competence, which is acquired gradually during oocyte growth and maturation in the ovarian follicle, 
A
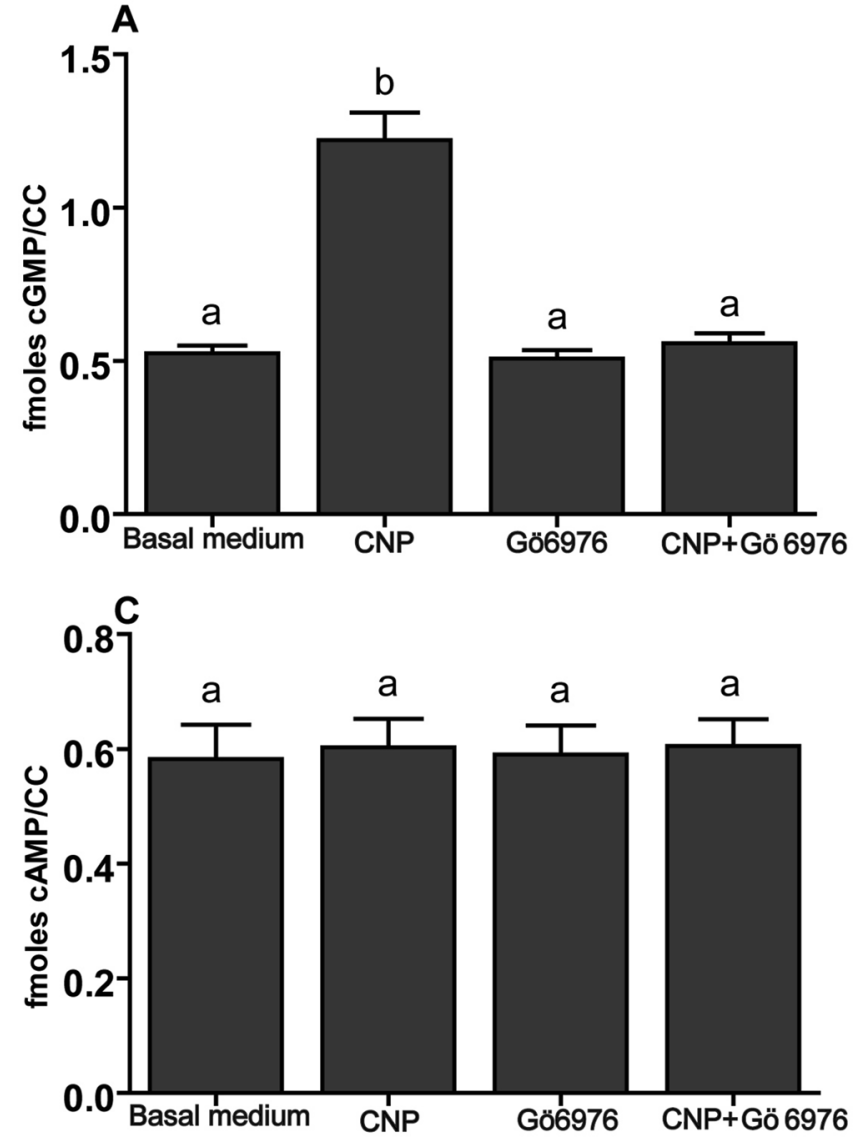

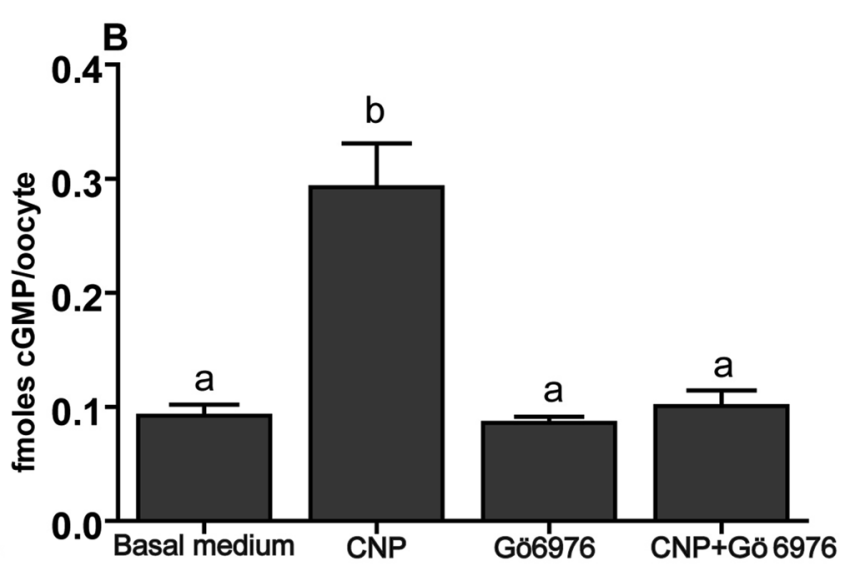

D

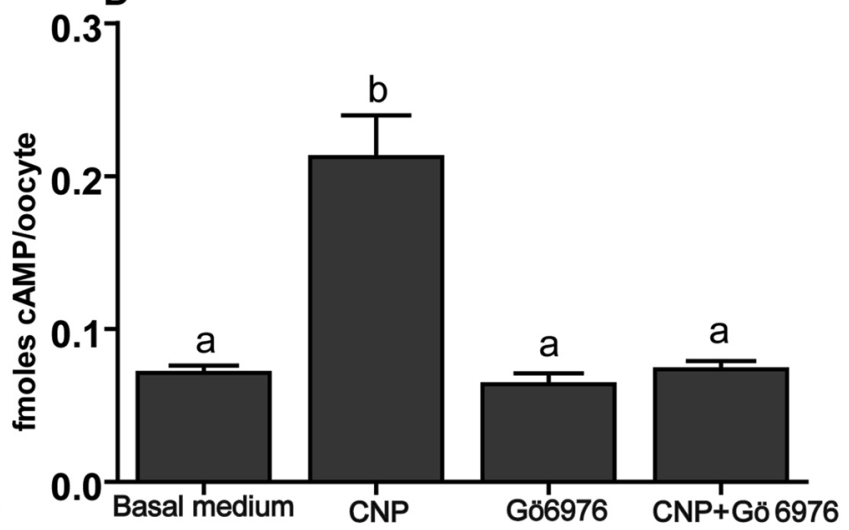

Figure 4. Inhibition of NPR2 abolishes the effect of CNP on the levels of cGMP/cAMP in bovine cumulus cells and oocytes. COCs derived from ovarian antral follicle were cultured in basal medium in the absence or presence of $200 \mathrm{nM}$ CNP and/or $5 \mu \mathrm{M}$ Gö6976, a competitive inhibitor of NPR2 (Basal medium, CNP, Gö6976, and CNP + Gö6976, respectively) for $6 \mathrm{~h}$. The levels of cGMP/cAMP in bovine cumulus cells and oocytes were detected at the end of culture. (A) The levels of cGMP in bovine cumulus cells. (B) The levels of cGMP in bovine oocytes. (C) The levels of cAMP in bovine cumulus cells. (D) The levels of cAMP in bovine oocytes. Graphs show the mean \pm SEM values of four independent experiments; Values indicated by different letters are significantly different $(P<0.05)$.

\begin{tabular}{|l|l|l|l|l|}
\hline Group & Oocytes $(\mathrm{N})$ & Cleavage rate (\%) & Blastocyst rate (\%) & Total cell numbers of blastocyst (N) \\
\hline Conventional IVM (SFs) & 187 & $\begin{array}{l}52.4 \pm 3.0^{\mathrm{c}} \\
(\mathrm{N}=98)\end{array}$ & $\begin{array}{l}11.8 \pm 1.1^{\mathrm{c}} \\
(\mathrm{N}=22)\end{array}$ & $\begin{array}{l}104.3 \pm 4.8^{\mathrm{b}} \\
(\mathrm{N}=20)\end{array}$ \\
\hline CNP-pretreatment based IVM (SFs) & 178 & $\begin{array}{l}56.7 \pm 4.8^{\mathrm{c}} \\
(\mathrm{N}=101)\end{array}$ & $\begin{array}{l}14.0 \pm 1.4^{\mathrm{c}} \\
(\mathrm{N}=25)\end{array}$ & $\begin{array}{l}106.3 \pm 6.2^{\mathrm{b}} \\
(\mathrm{N}=22)\end{array}$ \\
\hline Conventional IVM (MFs) & 188 & $\begin{array}{l}73.0 \pm 4.0^{\mathrm{b}} \\
(\mathrm{N}=138)\end{array}$ & $\begin{array}{l}23.4 \pm 2.7^{\mathrm{b}} \\
(\mathrm{N}=44)\end{array}$ & $\begin{array}{l}108.2 \pm 5.3^{\mathrm{b}} \\
(\mathrm{N}=23)\end{array}$ \\
\hline CNP-pretreatmentbased IVM (MFs) & 176 & $\begin{array}{l}86.9 \pm 2.7^{\mathrm{a}} \\
(\mathrm{N}=153)\end{array}$ & $\begin{array}{l}38.1 \pm 3.0^{\mathrm{a}} \\
(\mathrm{N}=67)\end{array}$ & $\begin{array}{l}127.1 \pm 6.3^{\mathrm{a}} \\
(\mathrm{N}=25)\end{array}$ \\
\hline
\end{tabular}

Table 1. Effects of the novel IVM system based on CNP-pretreatment on developmental competence of bovine oocyte derived from follicles of different sizes. Data are expressed as mean \pm SEM of four independent experiments. Blastocyst rate is calculated based on the number of the oocytes. Different superscripted letters in the same column indicate a statistically significant difference $(P<0.05)$.

is regulated by a number of signals molecules as well as cumulus cells ${ }^{41-43}$. Furthermore, previous studies have shown that COCs derived from SFs lack the ability to respond to regulatory and specific ligands because of an immature signaling capacity ${ }^{44-46}$. Thus, we hypothesized that during CNP pre-IVM period, the signaling networks in oocytes and surrounding cumulus cells from SFs, which participate in the development of oocyte competence, might be insufficient for promoting oocyte cytoplasmic maturation compared to those in oocytes and surrounding cumulus cells from MFs. Therefore, to develop more effective culture systems, further studies 
should focused on how to enhance the signaling capacity of COCs from SFs by supplementing with some regulatory factor during CNP pre-IVM period.

In summary, CNP increased the levels of cGMP in both cumulus cells and the oocyte from different follicle size through activation of NPR2, thereby sustaining meiotic arrest in bovine oocyte. In addition, CNP pre-IVM treatment enhanced the developmental potencial of bovine oocytes obtained from MFs, but had no effect on the developmental competence of bovine oocytes obtained from SFs.

\section{Materials and methods}

Our research was approved by the Laboratory Animal Resource Center of Inner Mongolia University for the Nationalities and was performed in accordance with the Animal Care and Use Statute of China.

Chemicals. Unless otherwise stated, all chemicals and reagents used were purchased from Sigma-Aldrich (St. Louis, MO, USA). HEPES-buffered tissue culture medium 199 (HTCM199, 12340-030) and TCM199 (11150-059) were purchased from Life Technologies. Follicle stimulating hormone (FSH) and luteinizing hormone (LH) were purchased from Bioniche (Belleville, Canada).

Collection of cumulus cell-oocyte complexes (COCs) and culture. COCs were collected from the antral follicles of bovine ovaries obtained from an local abattoir. Follicles were dissected with scissors at room temperature, measured under a stereomicroscope and separated into two groups according to diameter: small follicles, $<3 \mathrm{~mm}$; medium, 3-8 mm. COCs were liberated by carefully rupturing the follicles ${ }^{16}$. The COCs with more than three cumulus cells layers and a uniform ooplasm were selected and washed in the basal culture medium (TCM199 with Earle's salts supplemented with $0.4 \%$ fatty acid-free BSA) for subsequent study ${ }^{12}$. To examine the effects of CNP on oocyte meiotic arrest and the levels of cAMP and cGMP in bovine COCs, the COCs were cultured in basal medium with or without $200 \mathrm{nM} \mathrm{CNP}$ for $6 \mathrm{~h}^{11}$. All COCs were cultured at $38.5^{\circ} \mathrm{C}$ under 5\% CO2 in humidified atmosphere.

The assessment of oocyte meiosis arrest. To evaluate meiosis arrest in bovine oocytes, after $6 \mathrm{~h}$ of culture, cumulus cells were removed from COCs by using $5 \mathrm{mg} / \mathrm{ml}$ hyaluronidase in TCM199 medium and repeated pipetting, Denuded oocytes were fixed in $4 \%$ paraformaldehyde for $30 \mathrm{~min}$ at room temperature, permeabilized using $0.1 \%$ Triton-100 in PBS for $20 \mathrm{~min}$, and stained using 4',6-diamidino-2-phenylindole (DAPI). Oocytes with germinal vesicles (GV; meiotic arrest) were detected using a fluorescence microscope (Eclipse Ci-s; Nikon).

Measurement of cGMP and cAMP levels in cumulus cells and oocytes. The cGMP and cAMP levels in bovine CCs and oocyte were detect as described previously ${ }^{11}$ (Xi et al. 2018). Briefly, after $6 \mathrm{~h}$ of culture, groups of 50 COCs were collected. To obtain both the cumulus cells and the associated oocytes, the COCs were mechanically dissociated by manual pipetting with a small bore glass pipette in TCM199 containing $2 \mathrm{mM}$ IBMX. After a rapid wash with PBS containing $2 \mathrm{mM}$ IBMX, the CCs and DOs were transferred to $100 \mathrm{ml}$ of $0.1 \mathrm{M} \mathrm{HCl}$ for $25 \mathrm{~min}$ to lyse the cells and the tubes were then centrifuged at $13,000 \mathrm{~g}$ for $5 \mathrm{~min}$, the supernatant was transferred to new tubes and stored at $-80^{\circ} \mathrm{C}$ until assayed using the cGMP and cAMP enzyme-linked immunosorbent assay kit, according to the manufacturer's instructions. Eeach experiment was repeated independently at least four times.

In vitro maturation, fertilization and culture. Conventional in vitro maturation (IVM) was performed as previously described ${ }^{47}$. Briefly, COCs were matured in $500 \mu \mathrm{l}$ TCM199 supplemented with $10 \mu \mathrm{g} / \mathrm{ml} \mathrm{FSH}$, $1 \mu \mathrm{g} / \mathrm{ml} \mathrm{LH}$ and $1 \mu \mathrm{g} / \mathrm{ml}$ estradiol for $24 \mathrm{~h}$ in 4 -well culture plates (Nunclon; VWR, Bridgeport, NJ, USA) at $38.5{ }^{\circ} \mathrm{C}$ under $5 \% \mathrm{CO}_{2}$ in humidified atmosphere. To evaluate the effect of $\mathrm{CNP}$ pretreatment on the developmental potential of oocyte derived from follicles of different sizes, oocytes were matured in basal culture medium with $200 \mathrm{nM} \mathrm{CNP}$ for $6 \mathrm{~h}$, then subjected to an extended IVM culture for $28 \mathrm{~h}^{11}$ (Xi et al. 2018). After maturation, the COCs were fertilized in $\mathrm{BO}$ medium for $6 \mathrm{~h}$ at $38.5^{\circ} \mathrm{C}$ under $5 \% \mathrm{CO} 2$ in humidified atmosphere. After in vitro fertilization (IVF), the presumptive zygotes were transferred to $100 \mu \mathrm{l}$ CR 1 culture medium droplets at $38.5^{\circ} \mathrm{C}$ under $5 \% \mathrm{CO} 2$ in humidified atmosphere. The culture medium was changed every 2 days during the culture period. The cleavage and blastocyst rates were recorded on day 2 and 7 after fertilization, respectively.

Blastocyst cell number assessment. On day 7 of culture, blastocysts were fixed for 30 min with $4 \%$ paraformaldehyde in PBS, then stained for $10 \mathrm{~min}$ with Hoechst $33242(10 \mu \mathrm{g} / \mathrm{ml})$ in PBS containg $0.5 \%(\mathrm{v} / \mathrm{v})$ Triton $\mathrm{X}-100$. Embryos were mounted on slides and examined using a fluorescence microscope (Eclipse Ci-s; Nikon).

Statistical analysis. All data are presented as the mean \pm standard error of the mean. All proportional data were subjected to arcsine transformation before statistical analysis. All data obtained in the present study were assessed using one-way analysis of variance (ANOVA) followed by Duncan's test using SPSS version 12.0, (SPSS, Chicago, IL, USA). Statistical significance was defined as $P<0.05$.

Received: 31 July 2020; Accepted: 7 October 2020

Published online: 26 October 2020 


\section{References}

1. Leibfried-Rutledge, M. L., Critser, E. S., Eyestone, W. H., Northey, D. L. \& First, N. L. Development potential of bovine oocytes matured in vitro or in vivo. Biol. Reprod. 36, 376-383 (1987).

2. Rizos, D., Ward, F., Duffy, P., Boland, M. P. \& Lonergan, P. Consequences of bovine oocyte maturation, fertilization or early embryo development in vitro versus in vivo: implications for blastocyst yield and blastocyst quality. Mol. Reprod. Dev. 61, 234-248 (2002).

3. Blondin, P., Coenen, K., Guilbault, L. A. \& Sirard, M. A. In vitro production of bovine embryos: developmental competence is acquired before maturation. Theriogenology 47, 1061-1075 (1997).

4. Coticchio, G. et al. Oocyte maturation: gamete-somatic cells interactions, meiotic resumption, cytoskeletal dynamics and cytoplasmic reorganization. Hum. Reprod. Update 21, 427-454 (2015).

5. Edwards, R. G. et al. Maturation in vitro of mouse, sheep, cow, pig, rhesus monkey and human ovarian oocytes. Nature 208, 349-351 (1965).

6. Iwata, N. et al. Effect of interactions between granulosa and thecal cells on meiotic arrest in bovine oocytes. J. Reprod. Fertil. 100, 151-156 (1994).

7. Vivarelli, E., Conti, M., DeFelici, M. \& Siracusa, G. Meiotic resumption and intracellular cAMP levels in mouse oocytes with compounds which act on cAMP metabolism. Cell. Differ. 12, 1170-1172 (1983).

8. Aberdam, E., Hanski, E. \& Dekel, N. Maintenance of meiotic arrest in isolated rat oocytes by the invasive adenylate cyclase of Bordetella pertussis. Biol. Reprod. 36, 530-535 (1987).

9. Senthilkumaran, B. Recent advances in meiotic maturation and ovulation: comparing mammals and pisces. Front. Biosci. (Landmark Ed.) 16, 1898-1914 (2011).

10. Zhang, M., Su, Y. Q., Sugiura, K., Xia, G. \& Eppig, J. J. Granulosa cell ligand NPPC and its receptor NPR2 maintain meiotic arrest in mouse oocytes. Science 330, 366-369 (2010).

11. $\mathrm{Xi}$, G. et al. Natriuretic peptide receptor 2 (NPR2) localized in bovine oocyte underlies a unique mechanism for C-type natriuretic peptide (CNP)-induced meiotic arrest. Theriogenology 106, 198-209 (2018).

12. Franciosi, F. et al. Natriuretic peptide precursor C delays meiotic resumption and sustains gap junction-mediated communication in bovine cumulus enclosed oocytes. Biol. Reprod. 91, 61 (2014).

13. Soto-Heras, S., Paramio, M. T. \& Thompson, J. G. Effect of pre-maturation with C-type natriuretic peptide and 3-isobutyl-1-methylxanthine on cumulus-oocyte communication and oocyte developmental competence in cattle. Anim. Reprod. Sci. 202, 49-57 (2019).

14. Soto-Heras, S. et al. Biphasic in vitro maturation with C-type natriuretic peptide enhances the developmental competence of juvenile-goat oocytes. PLoS ONE 14, e0221663 (2019).

15. Blondin, P. \& Sirard, M. A. Oocyte and follicular morphology as determining characteristics for developmental competence in bovine oocytes. Mol. Reprod. Dev. 41, 54-62 (1995).

16. Lequarre, A. S. et al. Influence of antral follicle size on oocyte characteristics and embryo development in the bovine. Theriogenology 63, 841-859 (2005).

17. Tsafriri, A., Chun, S. Y., Zhang, R., Hsueh, A. J. \& Conti, M. Oocyte maturation involves compartmentalization and opposing changes of cAMP levels in follicular somatic and germ cells: studies using selective phosphodiesterase inhibitors. Dev. Biol. 178, 393-402 (1996).

18. Vaccari, S., Horner, K., Mehlmann, L. M. \& Conti, M. Generation of mouse oocytes defective in cAMP synthesis and degradation: endogenous cyclic AMP is essential for meiotic arrest. Dev. Biol. 316, 124-134 (2008).

19. Pirino, G., Wescott, M. P. \& Donovan, P. J. Protein kinase A regulates resumption of meiosis by phosphorylation of Cdc25B in mammalian oocytes. Cell Cycle 8, 665-670 (2009).

20. Richard, F. J., Tsafriri, A. \& Conti, M. Role of phosphodiesterase type 3A in rat oocyte maturation. Biol. Reprod. 65, 1444-1451 (2001).

21. Thomas, R. E., Armstrong, D. T. \& Gilchrist, R. B. Differential effects of specific phosphodiesterase isoenzyme inhibitors on bovine oocyte meiotic maturation. Dev. Biol. 244, 215-225 (2002).

22. Norris, R. P. et al. Cyclic GMP from the surrounding somatic cells regulates cyclic AMP and meiosis in the mouse oocyte. Development 136, 1869-1878 (2009).

23. Sasseville, M. et al. Characterization of novel phosphodiesterases in the bovine ovarian follicle. Biol. Reprod. 81, 415-425 (2009).

24. Aktas, H., Wheeler, M. B., Rosenkrans, C. F. Jr., First, N. L. \& Leibfried-Rutledge, M. L. Maintenance of bovine oocytes in prophase of meiosis I by high [cAMP]i. J. Reprod. Fertil. 105, 227-235 (1995).

25. Lévesque, J. T. \& Sirard, M. A. Effects of different kinases and phosphatases on nuclear and cytoplasmic maturation of bovine oocytes. Mol. Reprod. Dev. 42, 114-121 (1995).

26. Rose-Hellekant, T. A. \& Bavister, B. D. Roles of protein kinase A and C in spontaneous maturation and in forskolin or 3-isobutyl1-methylxanthine maintained meiotic arrest of bovine oocytes. Mol. Reprod. Dev. 44, 241-249 (1996).

27. Bilodeau, S., Fortier, M. A. \& Sirard, M. A. Effect of adenylate cyclase stimulation on meiotic resumption and cyclic AMP content of zona-free and cumulus-enclosed bovine oocytes in vitro. J. Reprod. Fertil. 97, 5-11 (1993).

28. Avery, B., Hay-Schmidt, A., Hyttel, P. \& Greve, T. Embryo development, oocyte morphology, and kinetics of meiotic maturation in bovine oocytes exposed to 6-dimethylaminopurine prior to in vitro maturation. Mol. Reprod. Dev. 50, 334-344 (1998).

29. Kubelka, M., Motlik, J., Schultz, R. M. \& Pavlok, A. Butyrolactone I reversibly inhibits meiotic maturation of bovine oocytes, Without influencing chromosome condensation activity. Biol. Reprod. 62, 292-302 (2000).

30. Mermillod, P., Tomanek, M., Marchal, R. \& Meijer, L. High developmental competence of cattle oocytes maintained at the germinal vesicle stage for 24 hours in culture by specific inhibition of MPF kinase activity. Mol. Reprod. Dev. 55, 89-95 (2000).

31. Hashimoto, S., Minami, N., Takakura, R. \& Imai, H. Bovine immature oocytes acquire developmental competence during meiotic arrest in vitro. Biol. Reprod. 66, 1696-1701 (2002).

32. Hiradate, Y., Hoshino, Y., Tanemura, K. \& Sato, E. C-type natriuretic peptide inhibits porcine oocyte meiotic resumption. Zygote 22, 372-377 (2014).

33. Zhang, J., Wei, Q., Cai, J., Zhao, X. \& Ma, B. Effect of C-type natriuretic peptide on maturation and developmental competence of goat oocytes matured in vitro. PLoS ONE 10, e0132318 (2015).

34. Zhang, Y. et al. Natriuretic peptides improve the developmental competence of in vitro cultured porcine oocytes. Reprod. Biol. Endocrinol. 15, 41 (2017).

35. Sanchez, F. et al. Biphasic in vitro maturation (CAPA-IVM) specifically improves the developmental capacity of oocytes from small antral follicles. J. Assist. Reprod. Genet. 36, 2135-2144 (2019).

36. De Sousa, P. A., Watson, A. J., Schultz, G. A. \& Bilodeau-Goeseels, S. Oogenetic and zygotic gene expression directing early bovine embryogenesis. Mol. Reprod. Dev. 51, 112-121 (1998).

37. Caixeta, E. S., Ripamonte, P., Franco, M. M., Junior, J. B. \& Dode, M. A. Effect of follicle size on mRNA expression in cumulus cells and oocytes of Bos indicus: an approach to identify marker genes for developmental competence. Reprod. Fertil. Dev. 21, 655-664 (2009).

38. Albuz, F. K. et al. Simulated physiological oocyte maturation (SPOM): a novel in vitro maturation system that substantially improves embryo yield and pregnancy outcomes. Hum. Reprod. 25, 2999-3011 (2010). 
39. Aardema, H. et al. Oleic acid prevents detrimental effects of saturated fatty acids on bovine oocyte developmental competence. Biol. Reprod. 85, 62-69 (2011).

40. Arat, S. et al. Effect of growth factors on oocyte maturation and allocations of inner cell mass and trophectoderm cells of cloned bovine embryos. Zygote 24, 554-562 (2016).

41. Sanchez, F. \& Smitz, J. Molecular control of oogenesis. Biochim. Biophys. Acta. 1822, 1896-1912 (2012).

42. McGinnis, L. K., Limback, S. D. \& Albertini, D. F. Signaling modalities during oogenesis in mammals. Curr. Top. Dev. Biol. 102, 227-242 (2013).

43. Biase, F. H. \& Kimble, K. M. Functional signaling and gene regulatory networks between the oocyte and the surrounding cumulus cells. BMC. Genomics 19, 351 (2018).

44. Kwak, S. S. et al. The new system of shorter porcine oocyte in vitro maturation $(18 \mathrm{~h})$ using $\geq 8 \mathrm{~mm}$ follicles derived from cumulusoocyte complexes. Theriogenology 81, 291-301 (2014).

45. Sugimura, S. et al. Promotion of EGF receptor signaling improves the quality of low developmental competence oocytes. Dev. Biol. 403, 139-149 (2015).

46. Yang, M. et al. Oocytes from small and large follicles exhibit similar development competence following goat cloning despite their differences in meiotic and cytoplasmic maturation. Theriogenology 86, 2302-2311 (2016).

47. Maclellan, L. J. et al. Influence of the luteinizing hormone-releasing hormone agonist, deslorelin, on patterns of estradiol-17 beta and luteinizing hormone secretion, ovarian follicular responses to superstimulation with follicle-stimulating hormone, and recovery and in vitro development of oocytes in heifer calves. Biol. Reprod. 56, 878-884 (1997).

\section{Acknowledgements}

This work was supported by Grants from the National Natural Science Foundation of China (Grant No. 31760670), the Natural Science Foundation of Inner Mongolia Autonomous Region of China (Grant No. 2019LH03018).

\section{Author contributions}

Z.J. designed and performed the experiments, and wrote the manuscript. X.W. took part in the design of study and the data collection and analysis.

\section{Competing interests}

The authors declare no competing interests.

\section{Additional information}

Correspondence and requests for materials should be addressed to Z.J.

Reprints and permissions information is available at www.nature.com/reprints.

Publisher's note Springer Nature remains neutral with regard to jurisdictional claims in published maps and institutional affiliations.

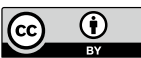

Open Access This article is licensed under a Creative Commons Attribution 4.0 International License, which permits use, sharing, adaptation, distribution and reproduction in any medium or format, as long as you give appropriate credit to the original author(s) and the source, provide a link to the Creative Commons licence, and indicate if changes were made. The images or other third party material in this article are included in the article's Creative Commons licence, unless indicated otherwise in a credit line to the material. If material is not included in the article's Creative Commons licence and your intended use is not permitted by statutory regulation or exceeds the permitted use, you will need to obtain permission directly from the copyright holder. To view a copy of this licence, visit http://creativecommons.org/licenses/by/4.0/.

(C) The Author(s) 2020 